\title{
Comment on: Influence of chronic kidney disease and haemodialysis on stroke outcome
}

Singapore Med J 2021; 62(11): 615 https://doi.org/10.11622/smedj.2021229

Dear Sir,

We read with great interest the article 'Influence of chronic kidney disease and haemodialysis on stroke outcome' by Pande and Morris. ${ }^{(1)}$ We would like to add an interesting clinical finding of an ongoing study on a southern Brazilian cohort.

Cerebrovascular disease (CVD) is the main cause of neurological hospitalisation in our hospital. ${ }^{(2)}$ The development of CVD units, associated with new imaging and therapeutic techniques, has helped reduce the length of hospital stay among patients with CVD.

${ }^{(3,4)}$ However, the length of stay of patients with stroke could be related to many variables, including severity, age and comorbidities; as concluded in the article by Pande and Morris, kidney diseases are an important factor contributing to the long hospital stay and all the associated complications among patients with CVD.

We studied a total of 1,946 patients; $1,038(53.4 \%)$ of these were male and 908 (46.6\%) were female. More patients aged $70-$ 90 years $(n=608,31.2 \%)$ had a longer hospital stay; the duration of hospital stay was five days in $830(42.6 \%)$ patients, $6-10$ days in $712(36.6 \%)$ patients, $11-15$ days in 219 (11.3\%) patients and > 15 days in 185 (9.5\%) patients. Hospital stay depends on multiple factors, including clinical picture, multidisciplinary treatment, requirement of complementary tests, complications and social conditions.

I congratulate the authors for the article, which focuses on an interesting topic that will serve as a motivation for further studies.

Yours sincerely,

Otto J Hernandez Fustes $^{1,2}$, Carlos Arteaga Rodriguez $^{3}$

${ }^{1}$ InNeuro, Curitiba, Paraná, ${ }^{2} \mathrm{H}$ ospital das Nações, Curitiba, Paraná, ${ }^{3}$ Medicine Department, Universidade Positivo, Curitiba, Paraná, Brazil. otto.fustes@hc.ufpr.br

\section{References}

1. Pande SD, Morris J. Influence of chronic kidney disease and haemodialysis on stroke outcome. Singapore Med J 2021; 62:594-8.

2. Moreira A, Hernandez Fustes OJ, Arteaga Rodriguez C, et al. [Doenças neurológicas mais frequentes no pronto socorro de um hospital universitário]. Arq Neuropsiquiatr 2000; 58(S2):137. Portuguese.

3. Hernandez Fustes OJ, Arteaga Rodriguez C, Hernandez Fustes OJ. In-hospital mortality from cerebrovascular disease. Cureus 2020; 12 :e8652.

4. Kasemsap N, Vorasoot N, Kongbunkiat K, et al. Impact of intravenous thrombolysis on length of hospital stay in cases of acute ischemic stroke. Neuropsychiatr Dis Treat 2018; 14:259-64 